\title{
Seleksi Pemimpin High Potential Talent Dengan Strategi Parenting Program
}

\author{
Albert Prajartoro \\ PLN Pusdiklat, Indonesia \\ albert_prajartoro@yahoo.com
}

\begin{abstract}
PT PLN (Persero) has the potential of lacking leaders at the Top Managers and Middle Managers level in the next 10 years. It caused by a very rapid organizational development and delay in the regeneration due to zero growth in 1996-2001 and the existing programs have not been able to meet the needs. To anticipate this, Parenting Program is proposed to be a mentoring an counseling program for High Potential (HiPO) Talen to become a future PLN's leader with good character and excellent performance. This Program is applied by selecting employees who are in the HiPO criteria and constructed through the parenting program. This study resulted in the determination of Hipo Talent criteria and the criteria of the parent, as well as the proposed program in the form of flow chart and roadmap implementation, and program materials.
\end{abstract}

Keywords: High Potentials Talent, Parenting Program

\section{ABSTRAK}

PT PLN (Persero) berpotensi mengalami kekurangan pemimpin pada jenjang Manajer Atas dan Manajer Menengah pada 10 tahun mendatang. Hal ini disebabkan oleh pengembangan organisasi yang sangat cepat dan keterlambatan kaderisasi karena ada zero growth pada tahun 1996-2001 dan program yang ada belum bisa memenuhi kebutuhan. Untuk mengantisipasi hal di atas, Parenting Program diusulkan menjadi program pembinaan dan pendampingan bagi High Potential (HiPO) Talent untuk menjadi pemimpin PLN masa depan yang berkarakter dan unggul. Program ini diterapkan dengan cara memilih pegawai yang masuk dalam kriteria high potential dan dibina melalui parenting program. Kajian ini menghasilkan usulan kriteria penetapan Hipo Talent dan kriteria parent, serta usulan program dalam bentuk bagan alir dan roadmap pelaksanaan, dan materi program.

Kata Kunci: High Potentials Talent, Parenting Program, Pemimpin masa depan 


\section{KILAT}

Vol. 9, No. 1, April 2020, P-ISSN 2089-1245, E-ISSN 2655-4925

DOI: https://doi.org/10.33322/kilat.v9i1.846

\section{PENDAHULUAN}

Statistik tahun 2019 menunjukan adanya kesenjangan distribusi umur dan jenjang jabatan di PLN. Pada jabatan Manajer Menengah (MM) yang berumur $\leq 45$ tahun hanya 40 orang, sehingga berpotensi terjadi kekurangan kader untuk mengisi jenjang Manajer Atas (MA) pada 10 tahun mendatang [1]. Hal ini memerlukan percepatan untuk mengisi jenjang Supervisor Atas (SPVA) pada kelompok umur 26 sampai dengan 30 tahun, Manajer Dasar (MD) pada kelompok umur 31 sampai dengan 35 tahun, dan Manajer Menengah (MM) pada kelompok umur 36 sampai dengan 40 tahun. Selain itu perlu segera mencari High Potential (HiPO) Talent berumur muda dalam rangka persiapan dan percepatan karier untuk mengisi kekosongan pada jenjang jabatan tersebut.

Proses seleksi pemimpin PLN saat ini melalui program Executive Education (EE 3 sampai 1), yang tidak membedakan antara pegawai berkategori HiPO dan non HiPO. Kelemahan program ini masih belum mampu mengakselerasi kenaikan jabatan bagi HiPO Talent. Ariss, et all mengidentifikasi dua pemahaman yang berbeda dalam pengelolaan talenta, yaitu: pendekatan spesifik yang terbatas bagi karyawan yang berpotensi tinggi, dan pendekatan inklusif untuk semua karyawan [2]. Hal ini menunjukan perlunya pendekatan khusus bagi HiPO Talent di PLN.

Isu strategis PLN saat ini adalah kebutuhan pemimpin masa depan yang berkarakter untuk mampu bersaing dan tumbuh berkelanjutan [3]. Kajian ini bermaksud memberikan sumbangan pemikiran dalam pengelolaan SDM untuk HiPO Talent, dalam rangka mempersiapkan mereka menjadi pemimpin masa depan yang berkarakter untuk memastikan keberlanjutan perusahaan pada masa mendatang. Parenting program menjadi cara untuk mengelola HiPO Talent oleh pemimpin senior dengan melakukan touch points sehingga mampu memahami, mengembangkan, dan menjaga para talent [4].

\section{METODOLOGI}

\subsection{High Potential Talent (HiPO Talent)}

HiPO Talent adalah karyawan yang berdasarkan assessmen memiliki kemampuan, komitmen kepada organisasi, dan motivasi meningkatkan diri untuk berhasil pada level yang lebih tinggi dalam organisasi [5]. Meskipun berbagai organisasi mendefinisikan HiPO Talent secara berbeda sehingga kriteria dan cara pengelolaan berbeda-beda, namun esensinya yaitu sekumpulan orang yang akan menjadi pemimpin organisasi di masa depan [6]. Ada hal yang lebih penting daripada perbedaan pendefinisian, yaitu memahami karyawan HiPO Talent dalam organisasi. HiPO Talent perlu dikelola secara khusus, karena karyawan kategori ini menjadi pembeda bisnis yang kritis, dimana organisasi yang berhasil mengidentifikasi dan membangun pemimpin-pemimpin berpotensi tinggi menunjukan keunggulan kinerja melampaui rekan sebayanya [7]. 
Tabel 1. Panduan pemilihan Hipo Talent di PLN

\begin{tabular}{|c|c|c|c|}
\hline No. & Variabel & Kriteria & Penguji / Assesor \\
\hline \multirow[t]{5}{*}{ I. } & Portofolio & & \\
\hline & a. Level jabatan & Manajer Dasar dan Supervisor Atas & \multirow{4}{*}{ Divisi Talenta } \\
\hline & b. Lama jabatan & Minimal 2 tahun & \\
\hline & c. Nilai talenta & $\begin{array}{l}\text { Minimal Sangat Potential dalam tiga } \\
\text { semester terakhir }\end{array}$ & \\
\hline & d. Bahasa Inggris & Toefl minimal 550 & \\
\hline \multirow[t]{8}{*}{ II. } & Performance & & \\
\hline & \multirow{2}{*}{$\begin{array}{l}\text { a. KinerjaUnit / Bagian / } \\
\text { Sub Unit }\end{array}$} & a. Kinerja tertinggi & \multirow[b]{2}{*}{ SPKK } \\
\hline & & $\begin{array}{l}\text { b. Trend kinerja membaik dalam } 3 \\
\text { semester terakhir }\end{array}$ & \\
\hline & b. Prestasi & $\begin{array}{l}\text { Memiliki prestasi tingkat Nasional / } \\
\text { regional }\end{array}$ & Divisi Talenta \\
\hline & \multirow[t]{4}{*}{ c. Kemampuan IT } & a. Mampu mengoperasikan Microsoft & \multirow{4}{*}{ Divisi Talenta dan STI } \\
\hline & & $\begin{array}{l}\text { b. Berperan aktif dan aplikatif dalam } \\
\text { pemanfaatan Media Sosial (posting } \\
\text { info PLN) }\end{array}$ & \\
\hline & & $\begin{array}{l}\text { c. Memiliki kebiasaan dalam } \\
\text { pengelolaan Big Data }\end{array}$ & \\
\hline & & $\begin{array}{l}\text { d. Aktif dalam pemanfaatan perhitungan } \\
\text { komputer, Cloud, Al dan Robotic }\end{array}$ & \\
\hline \multirow[t]{4}{*}{ III. } & Assesmen & & \\
\hline & a. Aspirasi (aspiration) & \multirow{3}{*}{ Lulus seleksi assesment } & \multirow{3}{*}{ Assesment Center } \\
\hline & b. Kemampuan (ability) & & \\
\hline & $\begin{array}{ll}\text { c. } & \text { Keterikatan } \\
& \text { (angagement) }\end{array}$ & & \\
\hline
\end{tabular}

Pembinaan HiPO Talent di PLN yang efektif dimulai saat menjabat manajer lini pada jenjang SPVA dan MD. Meskipun banyak kriteria penetapan Hipo Talent, namun ada cara yang tepat dengan melakukan assessment tiga komponen utama, yaitu: Aspirasi (aspiration) untuk naik ke peran yang lebih tinggi, Kemampuan (ability) untuk menjadi lebih efektif dalam tanggungjawab dan peran yang lebih tinggi, dan Keterikatan (engagement) untuk berkomitmen pada organisasi [8]. Tabel 1 merupakan panduan pemilihan HiPO Talent.

\subsection{Parenting Model}

Parenting Model merupakan cara mendampingi dan mengasuh anak secara efektif untuk keberhasilannya. Konsep Parenting Competency Model digunakan karena penelitian menunjukan adanya hubungan yang signifikan antara kualitas parenting dan keberhasilan anak-anak [9]. Konsep ini diadobsi di perusahaan dengan asumsi pegawai HiPO Talent diperlakukan sebagai anak oleh pemimpin senior yang berperan menjadi pengasuh. Implementasi Parenting Model membutuhkan dua metode dasar pendampingan yaitu mentoring dan counseling. Parenting Competence merupakan kemampuan mengasuh anak secara efektif dengan syarat penggunaan pengetahuan, ketrampilan, kemampuan, tindakan atau tingkah laku, ciri-ciri, sikap, dan sejumlah komponen yang terkait dengan keberhasilan anak [9] (tabel 2). 


\section{KILAT}

Vol. 9, No. 1, April 2020, P-ISSN 2089-1245, E-ISSN 2655-4925

DOI: https://doi.org/10.33322/kilat.v9i1.846

Tabel 2. Kompetensi Parenting bagi pengasuh

\begin{tabular}{|c|c|c|c|c|}
\hline \multicolumn{5}{|c|}{ fundamental Parenting Competencies } \\
\hline No. & Kompetensi & Sub Kompetensi & Prasyarat & Keunggulan \\
\hline \multirow[t]{4}{*}{1} & \multirow[t]{4}{*}{$\begin{array}{l}\text { Kemampuan Kognitif } \\
\text { (Cognitive Ability) }\end{array}$} & \multirow[t]{2}{*}{$\begin{array}{l}\text { Pengetahuan } \\
\text { Dasar Parenting } \\
\text { (Basic knowledge } \\
\text { of parenting) }\end{array}$} & $\begin{array}{l}\text { Mengetahui dasar-dasar pengetahuan tentang cara } \\
\text { mengasuh, mengawasi, melindungi, dan mengelola } \\
\text { perilaku Hipo Talent. }\end{array}$ & $\begin{array}{l}\text { Mempersiapkan dengan mempelajari cara yang terbaik untuk } \\
\text { mengasuh, mengawasi, melindungi, dan mengelola perilaku } \\
\text { sambil memelihara hubungan yang kuat antara Bapak Asuh - } \\
\text { Anak Asuh. }\end{array}$ \\
\hline & & & $\begin{array}{l}\text { Memahami kebutuhan rutin, struktur kerja, disiplin, } \\
\text { dan konsistensi keseluruhan waktu. }\end{array}$ & $\begin{array}{l}\text { Memahami kebutuhan rutin, keseimbangan struktur kerja, } \\
\text { fleksibilitas dan disiplin hanya saat diperlukan. }\end{array}$ \\
\hline & & \multirow[t]{2}{*}{$\begin{array}{l}\text { Pemecahan } \\
\text { Masalah } \\
\text { (Problem solving) }\end{array}$} & $\begin{array}{l}\text { Mengantisipasi dan mengidentifikasi problem, } \\
\text { menggabungkan informasi, membuat dan } \\
\text { mengevaluasi alternatif solusi, dan mengambil } \\
\text { tindakan. }\end{array}$ & $\begin{array}{l}\text { Menggunakan alasan deduktif dan induktif, dan } \\
\text { mempertimbangkan kemungkinan solusi dan konsekwensi } \\
\text { sebelum bertindak. }\end{array}$ \\
\hline & & & $\begin{array}{l}\text { Memiliki pemahaman tentang peran dalam } \\
\text { penyelesaian masalah atau kapan memerlukan } \\
\text { bantuan pihak lain. }\end{array}$ & $\begin{array}{l}\text { Memiliki pemahaman tentang peran dalam penyelesaian } \\
\text { masalah dan berjuang keras untuk peningkatan diri. }\end{array}$ \\
\hline 3 & $\begin{array}{l}\text { Kepedulian Diri } \\
\text { (Self Care) }\end{array}$ & $\begin{array}{l}\text { Jejaring Sosial } \\
\text { (Social network) }\end{array}$ & $\begin{array}{l}\text { Membentuk jaringan sosial dengan anggota } \\
\text { perusahaan lain, stakeholder, pelanggan yang akan } \\
\text { mendukung tugas-tugas yang diperlukan. }\end{array}$ & $\begin{array}{l}\text { Secara aktif terlibat dalam hubungan persahabatan dan } \\
\text { kekeluargaan dengan cara yang saling menguntungkan. }\end{array}$ \\
\hline \multicolumn{5}{|c|}{ Functional Parenting Competencies } \\
\hline \multirow[t]{3}{*}{1} & \multirow[t]{3}{*}{$\begin{array}{l}\text { Petunjuk Perilaku } \\
\text { (Behavioral Guidance) }\end{array}$} & \multirow[t]{3}{*}{$\begin{array}{l}\text { Disiplin yang tepat } \\
\text { (Appropriate } \\
\text { discipline) }\end{array}$} & $\begin{array}{l}\text { Menyusun harapan yang beralasan untuk perilaku dan } \\
\text { peningkatan berdasarkan jenjang dan perkembangan, }\end{array}$ & $\begin{array}{l}\text { Menyusun petunjuk, perkiraan, dan alasan harapan untuk } \\
\text { perilaku dan peningkatan bersasakan jenjang dan } \\
\text { perkembangan. }\end{array}$ \\
\hline & & & Mengelola perilaku melalui praktek non penistaan & Model perilaku yang pantas. \\
\hline & & & $\begin{array}{l}\text { Tidak menghukum dengan perintah salah, } \\
\text { mempermalukan }\end{array}$ & $\begin{array}{l}\text { menggunakan sikap disiplin yang konsisten dalam rangka } \\
\text { penyemangat dan menghargai perilaku yang baik dari pada } \\
\text { menghunbung perilaku yang jelek }\end{array}$ \\
\hline 2 & $\begin{array}{l}\text { Promosi Kesehatan } \\
\text { Emosional } \\
\text { (Emotional Health } \\
\text { Promotion) }\end{array}$ & $\begin{array}{l}\text { Pengasuhan } \\
\text { (Nurturance) }\end{array}$ & $\begin{array}{l}\text { Meluangkan waktu untuk anak asuh, termasuk } \\
\text { berdiskusi, merespon kebutuhan bantuan, menunjuk- } \\
\text { an perhatian, afeksi yang akan membangkitkan } \\
\text { semangat. }\end{array}$ & $\begin{array}{l}\text { Meluangkan waktu secara reguler untuk anak asuh, termasuk } \\
\text { berdiskusi, merespon kebutuhan bantuan, menunjukan } \\
\text { perhatian, afeksi yang akan membangkitkan semangat. }\end{array}$ \\
\hline
\end{tabular}

\subsection{Parenting Program}

Kajian gap antara permasalahan korporat saat ini dan kondisi ideal kepemimpinan PLN masa depan dianalisis dengan menggunakan Root Cause Problem Solving (RCPS) yang menghasilkan usulan Parenting Program for HiPO Talent. Program ini dimulai dari proses seleksi talent yang meliputi portofolio, performance, dan assement, yang selanjutnya HiPO Talent mengikuti inhouse training dan menjalani program pengasuhan untuk mengembangkan lima kompetensi, yaitu kemampuan pemecahan masalah, kemampuan membangun jejaring kerja, pengembangan diri secara personal dan professional, pemahaman proses bisnis, serta kemampuan beradaptasi. 


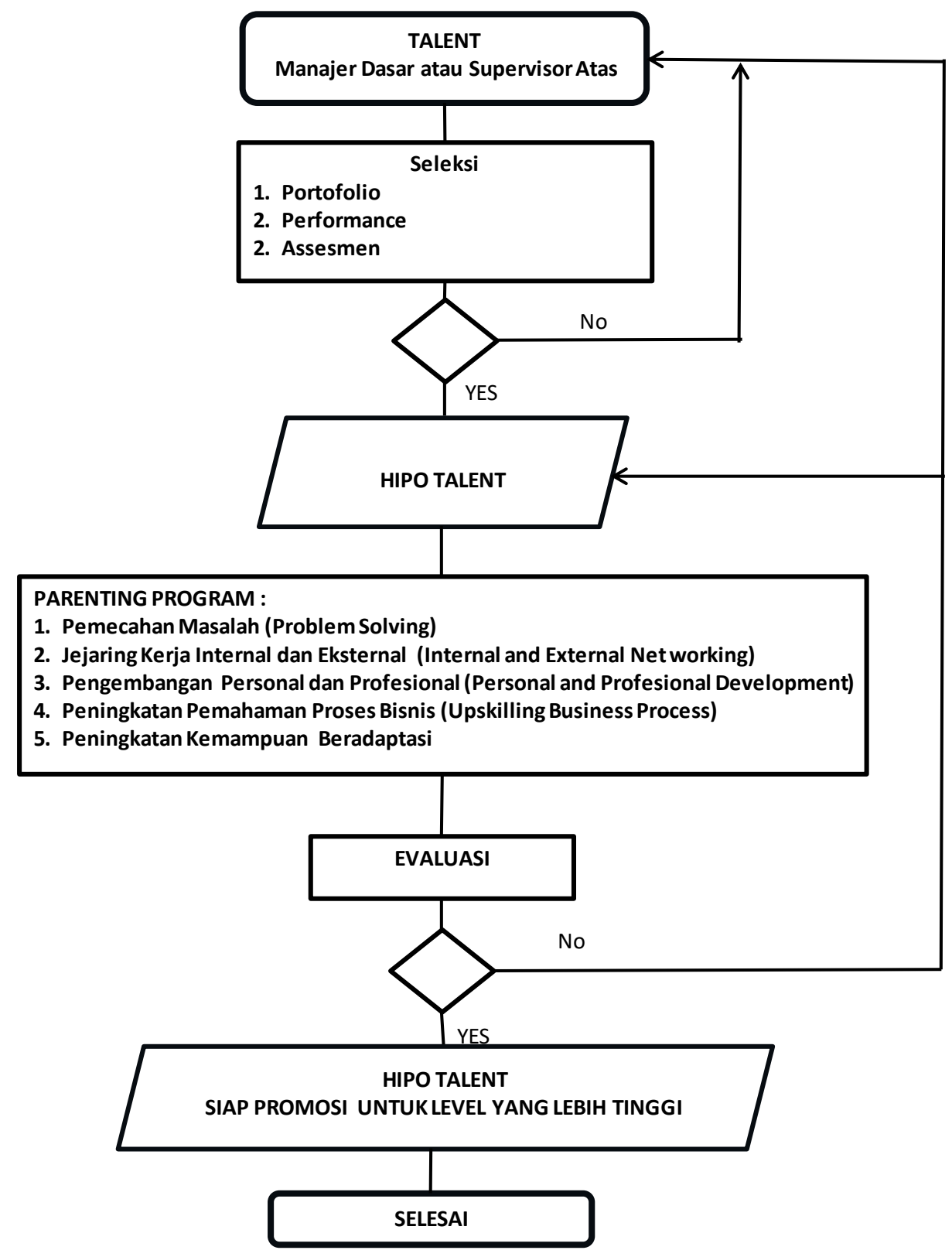

Gambar 1. Bagan alir pelaksanaan program

\subsection{Implementasi Program}

Program ini dilaksanakan secara bertahap yang diukur, dipantau dan dievaluasi setiap tahapnya. Tahap-tahap program tersebut sebagai berikut:

\section{Perancangan Program}

Tahap perancangan program membutuhkan waktu sekitar 6 bulan, dengan kegiatan: penetapan konsultan program, penyusunan metode pemilihan HiPO Talent dan metode pemilihan pengasuh, penyusunan materi workshop HiPO Talent dan materi workshop pengasuh, serta penyusunan schedule dan tools program. 


\section{KILAT}

Vol. 9, No. 1, April 2020, P-ISSN 2089-1245, E-ISSN 2655-4925

DOI: https://doi.org/10.33322/kilat.v9i1.846

\section{Persiapan Program}

Tahap persiapan membutuhkan waktu sekitar 3 bulan yang meliputi kegiatankegiatan: menyeleksi calon HiPO Talent (meliputi portofolio, performance, dan assessmen) dan menyeleksi pengasuh, penugasan pelaksana program (unit kerja dan tim), dan pemanggilan peserta.

\section{Pelaksanaan Program}

Tahap pelaksanaan program dirancang selama satu tahun yang meliputi kegiatan: workshop bagi pengasuh, workshop bagi HiPO Talent, penempatan peserta, pendampingan dan pengasuhan untuk mengembangkan kompetensi Pemecahan Masalah (Problem Solving), Jejaring Kerja Internal dan Eksternal (Internal and External Net Working), Peningkatan Pemahaman Proses Bisnis (Upskilling Business Process), dan Peningkatan Kemampuan Beradaptasi. Selama tahap ini dilakukan pengukuran dan pemantauan kemajuan program.

\section{Evaluasi dan Penilaian Akhir}

Tahap terakhir dilakukan sekitar 3 bulan untuk mengevaluasi dan menilai keseluruhan untuk menetapkan keberhasilan Hipo Talent. Hasil penilaian akhir apabila HiPO Talent dinyatakan kompeten dan lulus dalam program ini, maka yang bersangkutan siap untuk dipromosikan ke jenjang jabatan yang lebih tinggi. Apabila belum memenuhi kriteria dan masih kurang dalam proses pengasuhan, maka diberikan sekali lagi proses pengasuhan. Tetapi bila dinyatakan tidak memenuhi kriteria dan tidak lulus, maka yang bersangkutan dikembalikan sebagai talent pada jenjang jabatan sebelumnya.

\section{HASIL}

Hasil kajian tentang permasalahan pengelolaan HiPO Talent di PLN berupa Parenting Program mencakup usulan assesmen berupa panduan pemilihan Hipo Talent yang berisi kriteria pemilihan (tabel 1) dan kriteria kompetensi parenting bagi pengasuh (tabel 2). Tahap-tahap pelaksanaan program mengacu bagan alir agar dapat berjalan secara sistematis (gambar 1). Sedangkan pelaksanaan program terdiri atas perancangan program, persiapan program, pelaksanaan program, evaluasi dan penilaian akhir. Melalui program ini HiPO Talent diharapkan bertambah kompetensinya, yang meliputi kemampuan pemecahan masalah, kemampuan membangun jejaring kerja, pengembangan diri secara personal dan profesional, pemahaman proses bisnis, serta kemampuan beradaptasi yang diberikan melalui workshop dan pengasuhan.

\section{KESIMPULAN}

Kesimpulan dari program ini yang berkaitan dengan manfaat untuk menyelesaikan masalah sebagai berikut: Pertama, PLN memiliki program khusus bagi HiPO Talent dalam mempersiapkan mereka menjadi pemimpin masa depan, yang termotivasi untuk tetap berkarier di PLN, memiliki komitmen dan keterikatan yang lebih baik karena dengan adanya carrier path yang jelas. Kedua, Program ini bermanfaat untuk mengejar keterlambatan proses suksesi di jenjang Supervisor Atas (SPVA) dan Manajer Dasar (MD) sehingga dapat menyelesaikan potensi kekurangan pemimpin pada 10 tahun mendatang pada jenjang Manajer Atas (MA). 


\section{DAFTAR PUSTAKA}

[1] S. U. Februari, "Februari 2019 1.," no. 30, pp. 1-12, 2019.

[2] A. Al Ariss, W. F. Cascio, and J. Paauwe, "Talent management: Current theories and future research directions," J. World Bus., vol. 49, no. 2, pp. 173-179, 2014.

[3] D. I. Bisnis, "HUMAN CAPITAL."

[4] A. Pousette et al., "IMPACT OF SENIOR LEADER TOUCH POINTS ON HIGH POTENTIAL EMPLOYEE ENGAGEMENT AND RETENTION,” Implement. Sci., vol. 39, no. 1, pp. 1-15, 2014.

[5] A. Campbell, "Comments on 'Corporate strategy and parenting theory', Michael Goold, Andrew Campbell and Marcus Alexander. Long Range Planning, Volume 31, Issue 2, April 1998, Pages 308-314," Long Range Plann., vol. 50, no. 1, pp. 24-27, 2017.

[6] N. Zealand, "Hpiq - Defining and Measuring High Potential," vol. I, no. 2005, pp. 1-18, 2011.

[7] A. D. Klein, R. J. Pardo, E. Gould, and F. Kerdel, "Blue-Gray Discoloration of the Face," Arch. Dermatol., vol. 125, no. 3, pp. 417-418, 1989.

[8] SHL, "The HR Guide to Identifying High-Potentials," CEB SHL Talent Meas., pp. 1-18, 2014.

[9] B. D. Johnson, L. D. Berdahl, M. Horne, E. A. Richter, and M. gan Walters, "A Parenting Competency Model," Parenting, vol. 14, no. 2, pp. 92-120, 2014. 